\title{
Balance Scorecard Analysis and Business Model Generation
}

\author{
Arvy Rizaldy*, Vinus Maulina \\ Faculty of Economics \\ Universitas PGRI Kanjuruhan Malang \\ Malang, Indonesia \\ *Arvyrizaldy@gmail.com, vinusmaulina@unikama.ac.id
}

\begin{abstract}
This study aims to analyze the company's strategy using the balance scorecard (BSC) and business model generation (BMG) model. The BSC is a company performance measurement tool that aligns company goals based on four perspectives, while BMG is a description of the business model that the company runs based on nine blocks. This research was conducted at a rice milling company in Banyuwangi. Rice milling companies were chosen because of the incessant pressure from the government and the intense competition. Banyuwangi was chosen because this area is a granary for rice in East Java and one of Indonesia's granaries. The survey method by interviewing and using company secondary data were used in this study. The research object is PT. Agrinda Indoraya is a company engaged in rice milling and is located in Banyuwangi. The results showed that the BSC analysis from a financial perspective and an internal business perspective showed a good score (A), while from the customer perspective, the learning and growth perspective showed not too good scores (D and $B$ ). In addition, this study also shows that the description of the business model carried out by PT. Agrinda in several blocks needs improvement. Channel blocks, key resources and revenue stream blocks need improvement. Creating communication channels that make it easier for customers, adding waste processing machines and adding new product lines are imperative things to do.
\end{abstract}

Keywords-balance scorecard, business model generation, rice mill, Banyuwangi

\section{INTRODUCTION}

The rapid advancement of technology in everyday life in all aspects has driven many changes, especially in the business world towards globalization. The business world is forced to take part in the competition in producing products and services by following what the world wants [1]. This situation certainly encourages the business world to implement a strategy that is not only used to survive but also to compete both locally and globally, which in turn will give birth to companies that are highly competitive in the long term.

Currently in Indonesia there has been a shift in consumption behaviour patterns in society. This shift in the pattern of consumption behaviour is marked by the shift in people's purchasing power from commodity goods (non- leisure) to commodity leisure activities (leisure and lifestyle) [2]. The results of research conducted show a decrease in the level of consumption of non-leisure commodities from 2015 to 2017 for all segments. The decline in people's purchasing power for non-leisure commodity goods is inversely proportional to the increase in people's purchasing power for leisure and lifestyle commodities, so that it creates competition between companies which makes company performance important to be considered.

Banyuwangi Regency is one of the biggest contributors to East Java's rice with a production of 776,367 tons in 2017. The abundance of rice yields has relatively the same impact as the abundance of rice production in East Java, which provides opportunities as well as a challenge for rice milling businessmen in Banyuwangi. Research on the strategy of rice milling companies in Banyuwangi in maintaining and developing their milling business needs to be done.

One of the performance assessments is to use a balance scorecard (BSC). This BSC concept places a non-financial perspective as an important thing to be used as a good measuring tool in predicting an increase in the company's performance and survival in the future. The BSC concept was introduced in the USA by David P. Norton and Robert Kaplan through a study on "Performance Measurement in Future Organizations".

Research on BSC has been carried out before, including by [3-7]. However, performance measurement using the BSC also has weaknesses, one of which is that the BSC is still too general in describing strategic goals [8]. This weakness of the BSC is what makes researchers to add other measures that are more specific in describing strategy. Business Model Generation is a more specific performance measurement tool. Several studies using BMG [9-13].

PT. Agrinda Indoraya was chosen to be the object of this research. PT. Agrinda Indoraya was chosen because this company is one of the largest rice mills in Banyuwangi, so it is possible to obtain more complex yields. 


\section{RESEARCH METHODS}

This study uses qualitative methods to create a business strategy model at PT. Agrinda Indoraya using the Balance Scorecard Business Model Generation approach combined with the Business Model Generation approach. Qualitative research is scientific research whose purpose is to understand a phenomenon in a natural social context by promoting in- depth communication processes between researchers and the phenomena being studied. Qualitative research in this study uses a descriptive type. Where the purpose of this descriptive study is to describe the characteristics of a phenomenon. Descriptive research was conducted to answer the question of who, what, when, where and how.

The case study approach is the approach used in this research. The case study approach to qualitative descriptive research emphasizes the exploration of a system that is limited to a case or several cases in detail accompanied by in-depth data mining involving various sources of information.

\section{RESULTS AND DISCUSSION}

The following will be discussed based on two models, BSC and BMG:

\section{A. Balance Scorecard}

Performance measurement according to the balance scorecard in four perspectives (financial perspective, customer perspective, internal business process perspective and learning and growth perspective). These four perspectives will be measured based on their respective indicators. Financial perspective as an economic picture of the consequences of economic actions taken is measured based on ROI, ROE and NPM. Customer perspective that describes the position of the market segment where the company will compete is measured based on the level of product sales. The internal business perspective that describes the internal processes needed to provide value to owners and customers is measured based on the speed at which the company makes rice. Meanwhile, the learning and growth perspective that describes the capabilities needed by the company to create long-term growth and improved performance can be seen measured based on the investment made by the company, especially in the human resources section. From the results of the analysis of each perspective, a score is made to determine whether or not the assessment of each perspective is good [1].

The measurement of financial perspective uses profit analysis and company risk analysis. Profitability analysis is intended to measure the company's ability to produce during a certain period. It can also be used to measure the level of management effectiveness in operating the company. The score for ROI shows good performance in 2017 to 2019. This is evidenced by the acquisition of an A score for financial performance measured using ROI. ROI is calculated by comparing the company's profit with the investment the company makes. In addition to the A score, if you look at the amount of ROI for 3 years from 2017 to 2017, it has increased significantly. This proves that AIR is more effective in using its assets to generate profits for the company.

The third measure from a financial perspective is measured based on the NPM ratio (net profit margin) table 5.4. NPM is a ratio that shows how many\% of profit / margin the company earns. Of course, the larger the NPM, the better. The score results from the NPM indicator from a financial perspective show that AIR gets a score of A. which means that AIR has been able to generate good profits. Looking at the NPM calculation table proves that every year AIR always improves NPM, it is evident from 2017 to 2019 the amount of NPM has increased. In 2019, the amount of NPM was $3.36 \%$, meaning that $3.36 \%$ of AIR sales was net profit. Referring to 2019, it can be used to target profits in 2020, for example, the owner of AIR is targeting a profit of 3 billion, so the company must be able to sell products worth 89.28 billion during 2020 .

If in service companies this perspective is seen from the large number of customers who use the company's services, then in trading and manufacturing companies, this perspective is seen from the quantity of goods sold to consumers. To see how many items were sold, you can directly look at the company's income statement in the sales account. It can be seen that the number of company sales in 2016 amounted to 72 billion, in 2017 and 2018 amounted to 71 billion and 74 billion, respectively. In 2019 there was a decline in sales of 10 billion, which shows the size of sales of 64 billion.

An increase in the number of customers can be seen from an increase in the quantity of sales. If you look at the data, it shows that in the second year 2018 it got a good score than 2017 and 2019. The value score for the customer perspective is D in 2017 and 2019. This score shows the company's already good performance in terms of increasing the number of customers which in turn can increase the number / quantity of rice sold. Meanwhile, the score in 2018 shows the value of $\mathrm{A}$. If you see a decrease from 2018 to 2019.

The internal business perspective is measured or described based on the speed with which the company makes products. This speed can be related to the resources owned by the company. Meanwhile, machine resources are the company's actions to provide certain machines (investment) aimed at improving performance. In this case, AIR gets an A score for the provision of resources in the form of machines, this can be seen from the existence of advanced technology machines owned by AIR. Starting from drying machines to polishing machines which of course are intended to pamper AIR consumers.

Dryer machine is used as a grain drying machine. The capacity of the AIR drying machine is 40 tons. The existence of this drying machine allows AIR to not depend on sunlight when drying grain. So that the grain drying process becomes faster and AIR can save time in terms of providing goods to customers. The Kibi polishing machine is used to peel the husks of grain. AIR's Kibi engine capacity is 35 tons. The Kibi polishing machine makes AIR rice whiter, so it is able to attract consumers to buy AIR rice. Where most people choose rice 
with a white colour compared to rice with a dull colour, this is certainly an advantage for AIR.

Colour sorter machine is used to separate rice colours, dull and shiny colours. The existence of this machine provides benefits to AIR in maintaining the quality of the rice it sells mainly in terms of providing colours that match the specifications set by the company. This clearly gives AIR the advantage of being able to pamper consumers. A stoner machine is used to separate rice and stone. Not infrequently when we clean rice, there are small stones or gravel. AIR uses a stoner machine to make rice that is free from stones, thus allowing customers to be satisfied with AIR rice.

The learning and growth perspective is seen from the company's support for employee skills and development programs. This can be reflected in the number of actions the company has taken to involve employees in training in improving capabilities.

AIR includes only a few employees in certain training or seminars. For example, training conducted by the management following training in the use of human resources. In this training, according to the interviews conducted, it is aimed at how human resources are managed and placed. So that you will get the right $\mathrm{HR}$ and the right position.

From this perspective, the researcher sees that there is an unequal training for each human resource in AIR, so that AIR gets a B value for human resource management. There is a need for rotating training according to the position or authority in the company. If it was mentioned earlier that the management was involved in HR management training, then employees whose positions as staff can be included in certain seminars which are motivating employees / staff. In addition to seminars for staff, comparative studies can also be carried out to similar companies in other areas, this allows AIR to be able to learn together with other companies that hopefully can provide an experience to improve better performance.

\section{B. Business Model Generation}

In the business model generation, company strategies are described into nine blocks, customer segment, value proposition, channels, customer relationship, revenue stream, key resources, key activities, key partnership and cost structure.

Customer segment is a description of the consumer group (individual, organization) that the company wants to reach or serve, in this case the company is required to map which segment to target which means also to let other segments. The grouping of these segments is usually based on similarities in needs, behaviours and other attributes [14]. In this case, the grouping aims to find out what kind of customers the company will serve.

In this case AIR defines the Bali region as the main marketing area for its rice. Bali was chosen because of the economic level and the interest in the purchasing power of Balinese people for premium quality rice. In addition, there is still a lack of rice mills in Bali so that "Bali" is a fertile place to be able to market AIR's premium quality rice. Also supported by Bali as a tourist spot that demands to provide super quality rice.

Value Proposition is defined as an action taken to provide satisfaction to customers, which is of course tailored to the needs of consumers [14]. Activities carried out by AIR are not solely for the profit of the company, but must also consider satisfaction and benefits, especially for AIR consumers.

What AIR has done to make consumers feel satisfied is to create quality, friendly and beneficial products for consumers. To make white and smooth rice, many chemical products are sold freely in the market. This will certainly make the product sleeker, but it will definitely have an impact on consumer health. AIR chooses not to use hazardous chemicals, but AIR uses high-tech machines to produce rice that is white, slippery but not harmful to consumer health.

In this section, Osterwalder and Pigneur [14] explains how companies communicate with customers. AIR creates an effective communication channel between the company and its customers. Where each customer has the authority to be able to contact the marketing department. Every week, the customer is also contacted by the marketing department to inquire about stocks and arrange delivery plans.

AIR also has distributors in several regions, mainly in main marketing areas. This allows AIR to be able to deliver its goods quickly and distributors can distribute AIR's goods widely. Researchers feel the communication channels carried out by this company are still lacking, and need to take advantage of other means of communication. Researchers also feel that customers need more information than that, not only about ordering and shipping products. For example regarding product information, advantages and disadvantages, nutritional content and so on.

Customer relationship is defined as a way to maintain and establish good relationships between companies and customers [14]. States that customer relationship is a process that is carefully regulated by detailed information about individual consumers for all company consumers. Whose purpose is to maximize consumer loyalty. In this case AIR does the following ways to maintain good relationships with consumers.

First, AIR often makes visits to consumers. This is done once every three months. During visits made by AIR to consumers is to ask about complaints experienced by customers, perhaps from unsatisfactory products or services. In addition, this visit was conducted by AIR to confirm to customers regarding the amount of receivables. This confirmation aims to match accounts receivable records according to the company with accounts payable for customers. This matching aims to minimize the recognition between the customer and the company. Of course, with this kind of activity the customer will feel that he is accompanied by the company.

Second, AIR always provides feedback to consumers in the form of certain bonuses. Bonus is given by AIR to customers who can be considered productive. Productive or not is usually 
seen from the number of products that can be sold by customers. Simply put, the more a customer buys rice, the more productive it is for the company. These bonuses are given in the form of discounts or discounts on rice prices. Of course, with a program like this the customer will be more closely related to the company.

In contrast to the eighth block, if the eighth block describes the costs incurred by the company, this ninth block explains the revenue received by the company [14]. If we look at AIR's income statement, it shows that the income (revenue stream) comes from selling rice, selling groats and selling bran. The sales of rice are divided into medium rice and premium rice. Menir is a broken rice or it can be called a sort of medium rice. Meanwhile, bran is the husk of rice grain, usually AIR sells this bran to breeders to make animal feed.

Apart from selling rice, brackets are also sold in cash and credit. Katul is a by-product when rice mills grind rice. Katul is the bran of rice. AIR using the KIBI engine will certainly produce more bran than the one without the Kibi engine. Katul AIR is sold to companies engaged in the manufacture of animal feed. Katul is the main composition of animal feed in addition to corn. AIR sells its bran to PT. Vega Nusa Agriita which is engaged in animal husbandry. Sales of these brackets are made on a credit system and within 7 days from the date of shipment. Although this bran is not the main product produced by AIR, the sales proceeds can provide additional income for AIR. On average, if you look at data from 2017 to 2019, AIR sales can contribute $1-1.5 \%$ of AIR's total rice sales.

Key resources are defined as sources of raw materials used in production activities to provide value propositions to customers [14]. The main resources used in the company's production activities are of course something vital. The supply of unhulled rice and rice supplies from other rice mills need to be maintained by the company. AIR to maintain the availability of raw materials and the continuity of production, determines having iron stock for production for the next 2 months. This is used to anticipate harvest delays or raw material difficulties that may be experienced. Apart from raw materials, AIR also has high technology machines. This is also one of the main sources of AIR in supporting the availability of rice stocks.

However, researchers feel that this key resource is still missing something. Additional investment is needed in the form of a hammer mill machine. This machine is used to make production waste in the form of husks, into cosmetic raw materials. So far, AIR has regarded husks as a worthless leftover product, because the price is so low. For this reason, it is necessary to have innovation by utilizing technology that can change from discarded goods to valuable goods, so that it will become a source of additional income for the company. In addition, if this is done, it will turn the process that occurs in AIR into a "zero waste" production process, meaning that nothing is wasted during the production process, starting from raw materials to the rest.

Key activities as important actions that a company must take to maximize company performance [14]. The main activity of AIR as a company whose main activity is selling basic necessities in the form of rice, namely maintaining quality, product availability in the market and maintaining rice production in accordance with specified standards.

To maintain good quality rice, of course there are several things that need to be considered. First, is the input and second is the process. These two things will greatly determine the quality of the rice produced. Input comes from unhulled rice that farmers sell to AIR, the type of grain, the moisture content, determines whether the rice is good or not. The grain of the IR64 variety and the IF16 variety fari will undoubtedly give different forms of rice. The process is also an important part of turning unhulled rice into head (super), medium or regular rice. The longer process (many steps) will usually tend to produce super rice. In this process, the use of machines is closely related to the rice produced by AIR. Generally, the more sophisticated the machine used, the more it will make rice into the highest quality (premium) rice. The more rice has good quality, of course the selling price will also increase.

The cooperation relationship is very important to be done and maintained for the sustainability of AIR in the future. Stated that cooperation needs to be done for several specific reasons to support the model and business goals that have been set [14]. The objectives of the collaboration include maximizing company performance, reducing risk uncertainty and obtaining the resources the company needs. AIR has several partners in running its rice milling business.

AIR establishes partnerships with suppliers. The suppliers here are divided into two. The first supplier is farmers and the second supplier is a small rice mill company. AIR is a partner of farmers because farmers are the main source of raw materials in the form of grain needed by AIR. The system that AIR applies to farmers to maintain relationships (partnerships) is to provide soft loans to farmers to finance the farmers' rice care. For example, every farmer is given fertilizer provided by AIR. Farmers can take the fertilizer provided without paying for it at the time of collection, but on the condition that the rice yields are sold to AIR at harvest time, the proceeds from the sales will then be deducted by the amount of fertilizer the farmer has taken. Apart from fertilizers, AIR also provides soft loans in the form of cash to farmers. Later, farmers can borrow money from AIR. Of course, the size of this cash loan to farmers is based on how much rice fields the farmer owns, then multiplied by the standard of borrowing given.

The cost structure describes what costs are incurred to run the company's operations [14]. At AIR costs are grouped based on the nature and designation of the costs. If you look at AIR's financial report, of course the main expense is to buy raw materials in the form of unshelled rice, rice and bran. From the purchase of these raw materials, it can be seen that AIR not only buys unshelled rice from farmers, but AIR also buys rice from other rice mills. Apart from unshelled rice and rice, AIR also buys bran for processing and resale.

From the raw materials purchased, the process is then carried out. In carrying out the process there are several costs 
incurred until the raw materials are ready to be used for production. This cost is for example the cost for drying rice. For the drying process, it can be done in two ways, first using manual method (using human labour), and second using technology in the form of a dryer. The drying process in the first method certainly requires a fee, namely the daily wage of the drying officer.

\section{CONCLUSION}

The results of the financial analysis of PT. Agrinda Indoraya uses a balanced scorecard framework to show a good score. Financial, internal business, customer perspectives get an A score which means the company is able to use assets, innovation, investment and customer relationships to generate profits. The customer perspective gets a score of B, which means that the company is good at involving employees in several trainings but it is still not evenly distributed.

The results of the analysis using the BMG model showed good results in nine blocks. However, some blocks can still be repaired. The income stream can be added from income outside the company's main business by treating production waste. Relationships with customers can be improved by utilizing social media.

\section{REFERENCES}

[1] S. Anggraini and Retnani, "Penerapan Balance Scorecard sebagai Alat Pengukuran Kinerja pada Rumah Sakit Islam Surabaya,” J. ilmu dan Ris. Akunt., vol. 4, no. 11, pp. 1-24, 2015.

[2] Nielsen, "Perubahan Pola Perilaku Konsumsi Masyarakat," J. ilmu Manaj., vol. 3, no. 1, pp. 14-30, 2017.
[3] J. Kádárová, M. Durkáčová, K. Teplická, and G. Kádár, G. "The Proposal of an Innovative Integrated BSC-DEA Model,” Procedia Econ. Financ., vol. 23, pp. 1503-1508, 2015.

[4] Wasis, Rancangan Balanced Scorecard Sebagai Instrument Pengukuran Kinerja Di Rumah Sakit Citra Medika Sidoarjo. Tesis Univ. Airlangga, 2013.

[5] T. García-Valderrama, E. Mulero-Mendigorri, and D. Revuelta-Bordoy, "Relating the perspectives of the balanced scorecard for R\&D by means of DEA,” Eur. J. Oper. Res., vol. 196, no. 3, pp. 1177-1189, 2009.

[6] Y. Lee, Y. Hsieh, and Y. Chen, “An Investigation of Employess Use of E-Learning Systems, applying the technology acceptance model. Behaviour and Information Technology," Behav. Inf. Technol., vol. 32, no. 2, pp. 173-189, 2013.

[7] Q. Wang and X. Sun, "Investigating gameplay intention of the elderly using an Extended Technology Acceptance Model (ETAM)," Technol. Forecast. Soc. Change, vol. 107, pp. 59-68, 2016.

[8] R. Govindaraju, "Studi Mengenai Penerimaan istem ERP Enhancement Terhadap Model Penerimaan Sistem ERP Berbasis Technology Acceptance Model,” pp. 654-664, 2004.

[9] A. Joice and R.L. Paquin, "The Triple Layered Business Model Canvas: A Tool to Design More Sustainable Business Models," J. Clean. Prod., vol. 135, pp. 1474-1486, 2016.

[10] S.F. Keane, K.T. Cormican, and J.N. Sheahan, "Comparating How Entrepreneurs and Managers Represent the Element of The Business Model Canvas," J. Bus. Ventur. Insight, vol. 9, no. 65-74, 2018.

[11] M.A. Toro-Jarrín, I.E. Ponce-Jaramillo, and D. Güemes-Castorena, "Methodology for the Building Process Integration of Business Model Canvas and Technological Roadmap," Technol. Forecast. Soc. Chang., vol. 110, pp. 213-225, 2016.

[12] H. Abe, T. Ashiki, A. Suzuki, F. Jinno, and H. Sakuma, "Integrating business modeling and roadmapping methods-the innovation support technology (IST) approach," Chang, vol. 76, no. 1, pp. 80-90, 2010.

[13] W.T. Jackson, D.J. Scott, and N. Schwagler, "Using the business model canvas as a methods approach to teaching entrepreneurialfinance," Entrep. Educ., vol. 18, no. 2, pp. 99-118, 2015.

[14] A. Osterwalder and Y. Pigneur, "Designing business models and similar strategic objects: the contribution of IS," Journal of the Association for information systems, vol. 14, no. 5, p. 3, 2012. 